\title{
The influence of the cutting parameters on the pullout resistance of the M8 thread processed by tapping into the SikaBlock M960 material
}

\author{
Sandor Ravai-Nagy, ${ }^{1, *}$ \\ 1 Technical University of Cluj-Napoca, North University Center Baia Mare, Dr. V. Babeş str., 62A, \\ 430083, Baia Mare, Romania
}

\begin{abstract}
Given that polyurethane materials are used more and more often in the assembly line of light alloy parts or thin steel sheets, it is necessary to determine the most favourable cutting parameters. Based on the studies in the field of threads, I found that the cutting parameters have an influence on the internal tapped thread pullout resistance. In the experiments, I studied the M8 thread manufactured by tapping into the SikaBlock ${ }^{\circledR}$ M960 material.
\end{abstract}

\section{Introduction}

Polyurethane marketed under the names of SikaBlock, Necuron etc. are used more and more often in the production line equipment of the automotive industry, and not only.

They are used as a semi-finished product for parts families such as: foundry patterns and core boxes, metal sheet forming tools, mouldings and master models, moulds and tools for lower number of pieces, vacuum forming tools, Jigs and Fixtures element, master models etc.

Following a bibliographic study, I found no recommendations regarding the calculation and dimensioning of the threads processed in Polyurethane materials. From the point of view of the recommendations regarding the cutting parameters, I found such studies concerning milling [2], but no study for the threading method. Noting the lack of information, I conducted studies in this area to get information on the thread resistance by determining, measuring the screw pullout resistance. At the same time, I studied the effects of the cutting parameters by tapering on the machined thread.

Within this paper I present my own research regarding the resistance of the thread to the pullout forces.

\section{Performing the experiment}

I experimentally machined threaded holes with a tap, with different cutting speeds, after that each inner thread was loaded up to destruction.

For experiments, I chose the SikaBlock@M960 materials and M8 screw (ISO 4017).

\footnotetext{
* Corresponding author: Ravai.Nagy.Sandor@cunbm.utcluj.ro
} 
The SikaBlock ${ }^{@}$ M960 is a Polyurethane material with $1,2 \mathrm{~g} / \mathrm{cm}^{3}$ Density, $70 \mathrm{MPa}$ Flexural strength, $70 \mathrm{MPa}$ Compressive strength, D78 Shore hardness, $30 \mathrm{~kJ} / \mathrm{m}^{2}$ Impact resistance and 2,2 MPa E-Modulus. [1]

In the experiment, I use specimens in which are processed M8 threads with depth (length) $\mathrm{L}=\mathrm{D}$ and $\mathrm{L}=2 \mathrm{D}$ respectively. In the case of thread length $\mathrm{L}=2 \mathrm{D}$, the thickness of the specimen was 2D, i.e. $16 \mathrm{~mm}$ (Fig.1.a), in the case of $\mathrm{L}=\mathrm{D}$ the thickness remained $16 \mathrm{~mm}$, but each threaded hole was provided with a counterbore (Fig.1.b) leaving the thread length of $8 \mathrm{~mm}$.

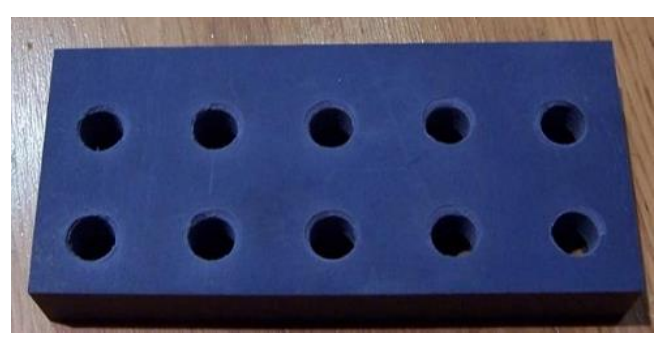

a.

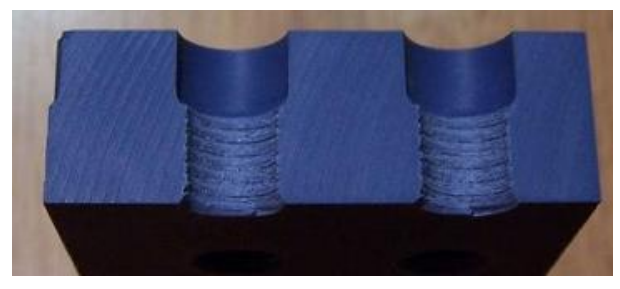

b.

Fig.1. Test specimens

In the thread machining use the following thread processing conditions with tap:

- Machine tool: G40 drilling machine

- Cutting tools:

- Twist drill bit 6,80 mm HSS DIN 345, for pilot hole;

- Cutting parameters: $\mathrm{n}=800 \mathrm{~min}-1, \mathrm{f}=0,22 \mathrm{~mm} / \mathrm{rev}$;

- Cooling / cutting fluid: emulsion, B-Cool 655 with a concentration of $6 \%$ (Blaser Swisslube AG).

- Machine tap, DIN 376, HSS-E, (6H), M8 x 1,25

- Cutting parameters:

- $\mathrm{n}=1400$ min-1, 1000 min-1, 710 min-1, 355 min-1, 90 min-1;

- $\mathrm{f}=1,25 \mathrm{~mm} / \mathrm{rev}$;

- Cooling / cutting fluid: emulsion, B-Cool 655 with a concentration of $6 \%$ (Blaser Swisslube AG);

- Tap type: for blind hole threads.

- Tool holder: Quick change tapping chuck with length compensation;

- Fastening system of the test specimen:

- Manual double axis cross tables, on which is fixed a vice;

- Machine tool vice, sits on the double axis cross tables, in which the specimen blank is fastened.

For machining a material, we choose cutting tools based on recommended cutting speed and feed rate. The cutting speeds used in the experiment, where they are determined by the spindle speeds of the drilling machine, are presented in Table 1

Table 1. The used cutting speeds for thread machining.

\begin{tabular}{|l|c|c|c|c|c|}
\hline Spindle speed, $\mathrm{n}\left[\mathrm{min}^{-1}\right]$ & 1400 & 1000 & 710 & 355 & 90 \\
\hline Tap diameter M8 & \multicolumn{5}{|c|}{$8 \mathrm{~mm}$} \\
\hline Cutting speed $[\mathrm{m} / \mathrm{min}]$ & 35.186 & 25.133 & 17.844 & 8.922 & 2.262 \\
\hline
\end{tabular}

The traction test of the threaded assembly was performed on a material test machine, TC100 made by LBG SRL Testing Equipment with maximum load $100 \mathrm{kN}$, equipped with a set of devices specially designed to fix the specimen and the screw, figure 2 . 

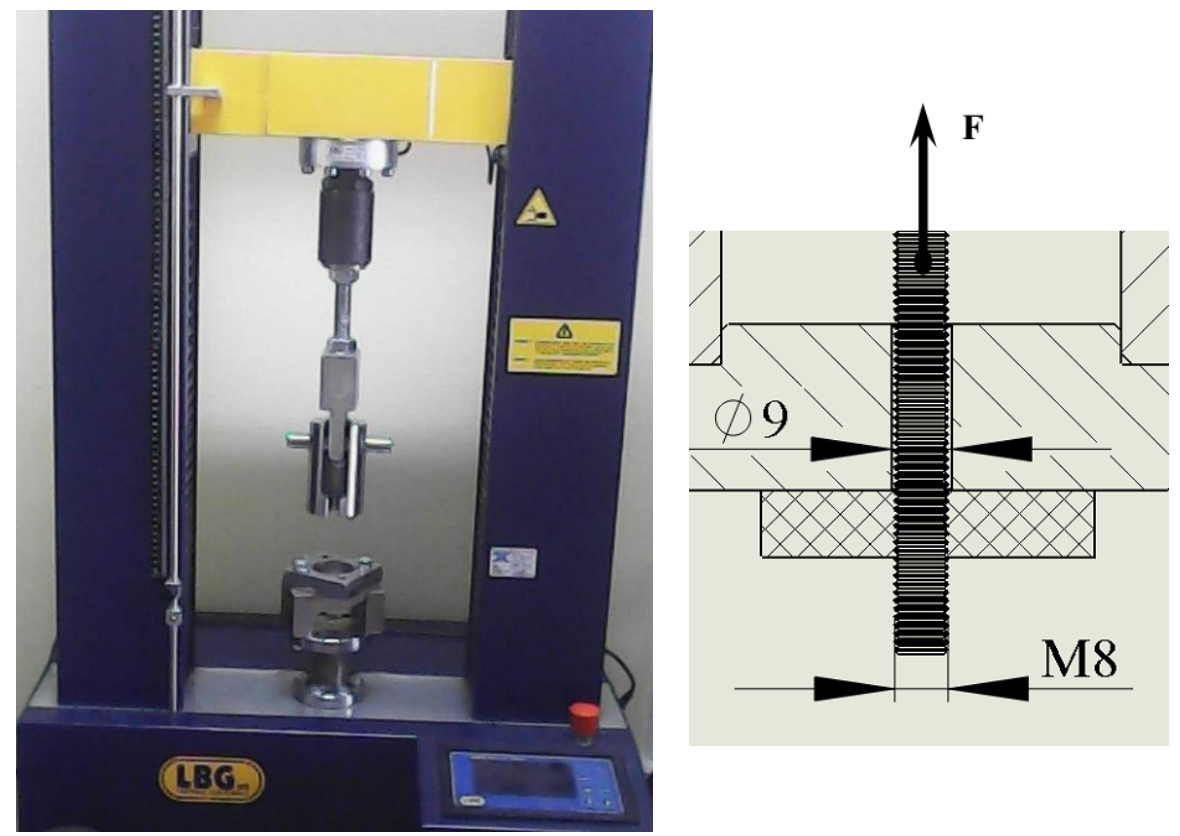

Fig.2. Materials testing machine TC100 equipped with the necessary devices for the specimen and the screw to measure the thread pullout resistance

The table 2 shows the experimental data obtained from thread testing and in Figure 4 are shows in graphical format.

Table 2. Experimental data obtained from thread test.

\begin{tabular}{|c|c|c|c|c|c|c|c|}
\hline & \multicolumn{2}{|c|}{$\mathrm{L}=\mathrm{D}(\mathrm{L}=8 \mathrm{~mm})$} & \multicolumn{2}{|c|}{$\mathrm{L}=2 \mathrm{D}(\mathrm{L}=16 \mathrm{~mm})$} & & \multirow[b]{3}{*}{$\begin{array}{c}\% \\
\text { vs. } \mathrm{F} / 12,8\end{array}$} \\
\hline & & \multicolumn{4}{|c|}{ thread pullout force } & & \\
\hline & & $\mathrm{F}$ & $\begin{array}{c}F / z \\
Z=6,4 \text { helix }\end{array}$ & $\mathrm{F}$ & $\begin{array}{c}\mathrm{F} / \mathrm{z} \\
\mathrm{Z}=12,8 \text { helix }\end{array}$ & & \\
\hline & & $\mathrm{kN}$ & $\mathrm{kN}$ & $\mathrm{kN}$ & $\mathrm{kN}$ & $\mathrm{kN}$ & $\%$ \\
\hline $\begin{array}{c}\mathrm{n} \\
{\left[\mathrm{min}^{-1}\right]}\end{array}$ & $\begin{array}{c}\mathrm{V} \\
{[\mathrm{m} / \mathrm{min}]}\end{array}$ & 1 & 2 & 3 & 4 & $\begin{array}{c}5 \\
(2-4)\end{array}$ & $\begin{array}{c}6 \\
(5 \times 100 / 4)\end{array}$ \\
\hline 1400 & 35.186 & 5.402 & 0.8441 & 10.688 & 0.8350 & 0.0090 & 1.08 \\
\hline 1000 & 25.133 & 5.437 & 0.8495 & 10.917 & 0.8529 & -0.00336 & -0.39 \\
\hline 710 & 17.844 & 5.463 & 0.8537 & 11.082 & 0.8658 & -0.01215 & -1.40 \\
\hline 355 & 8.922 & 5.497 & 0.8589 & 11.131 & 0.8696 & -0.01072 & -1.23 \\
\hline 90 & 2.262 & 5.507 & 0.8605 & 11.256 & 0.8793 & -0.01887 & -2.15 \\
\hline
\end{tabular}

Considering that the sizing and verification of the threaded assembly is based on the strength of one helix, I have calculated its resistance based on the experimental result.

Having no experimental data on uneven distribution of thread load along the axis of helix for the steel-SikaBlock ${ }^{@}$ M960 couple, in this case, by an equal distribution, I assign the same fraction of force on each thread helix.

In this study the experimental values are for the M8 thread [2,3] single start to which the helix lead is equal to linear pitch. For multi start thread (double thread, triple thread, ...), the studies will have to be repeated.

Calculating the number of coils for the length of thread $L=D, L=2 D$

The linear pitch of the M8 single start thread: $p=1,25 \mathrm{~mm}$

Number of pitches for the thread length $\mathrm{L}=\mathrm{D}$ : 


$$
z=\frac{L}{P}=\frac{8}{1.25}=6.4
$$

Number of pitches for the thread length $\mathrm{L}=2 \mathrm{D}$ :

$$
z=\frac{L}{P}=\frac{16}{1.25}=12.8
$$

In Table 2, columns 2 and 4 are presented the experimentally obtained pullout resistance for a single thread coil, depending on the thread cutting parameters.

Performing the tests with thread lengths $\mathrm{L}=\mathrm{D}$ and $\mathrm{L}=2 \mathrm{D}$ we could not analyze the problem of the uneven distribution of thread load along the axis of helix [4-6].

The scientific paper [4] presents a synthesis about the uneven distribution of thread load along the axis of helix based on the research conducted by Jukovski N.F., Paland G.E. and Maduschka L. Based on these studies, the first helix in contact takes about $35 \%$ of the screw load and the 6th helix takes less than 10\%. Also, the paper [5] presents this (figure $3)$. These observations are valid for the pair of steel-steel materials.

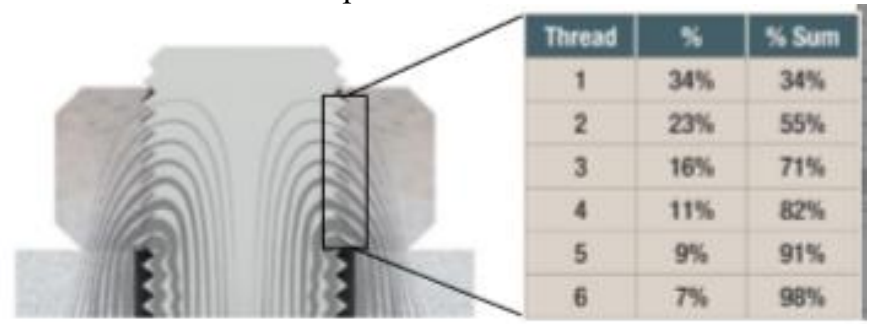

Figure 3. Load distribution in the paired tread [5, figure 9]

In the present work, by dividing the force by the number of helixes, we made only one allocation of force on each helix in order to compare them according to the performed test.

Considering that in the specialized literature the study was carried out on the pairs of metal - metal materials that have comparable mechanical properties (tensile strength, elongation, hardness etc.) in the case of SikaBlockM960 - steel having very different mechanical properties that can lead to a different behaviour from the pointed ones.

Only through an in-depth study in which we try samples with $1,2 \ldots 6,7$ and 8 helixes, I will be able to compare the distribution of the load on helixes in the case of SikaBlockM960 - steel materials with the percentages mentioned in the literature.

\section{Analysis of the results of the experiments}

Analysing the experimental data from table 2 and graphs $4 \mathrm{a}, 4 \mathrm{~b}$ I find, the resistance of the thread helix having a variation in the interval $+1.08 \% \ldots-2.15 \%$ for the studied cases, $\mathrm{L}=$ $D$ respectively $\mathrm{L}=2 \mathrm{D}$. So, I consider:

- from the point of view of equipment design we obtained information with which we can size and verify a threaded assembly M8;

- from the point of view of the uneven distribution of thread load along the axis of helix it is necessary to deepen the studies.

Figure 5 shows the graph of the load force variation for the threaded assembly obtained from the material testing machine.

In terms of deformations, in the graph on the axis of deformations appears the deformations of the technological test assembly and not of the thread helix. The technological assembly used in the experiment does not allow me to measure only the deformation of the thread helix. 

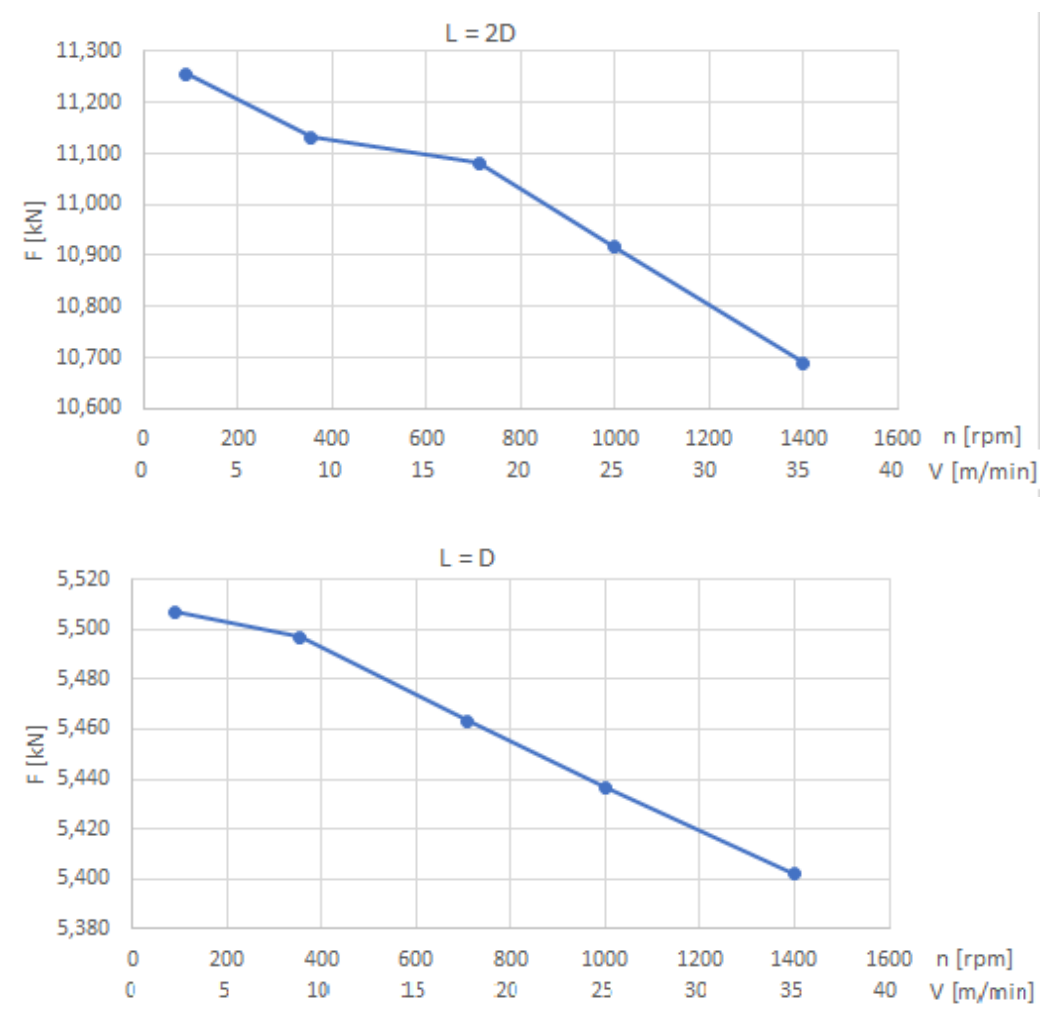

Figure 4.a. Graphical representation of the results of the experiments, coordinate system: cutting speeds - thread pullout resistance.

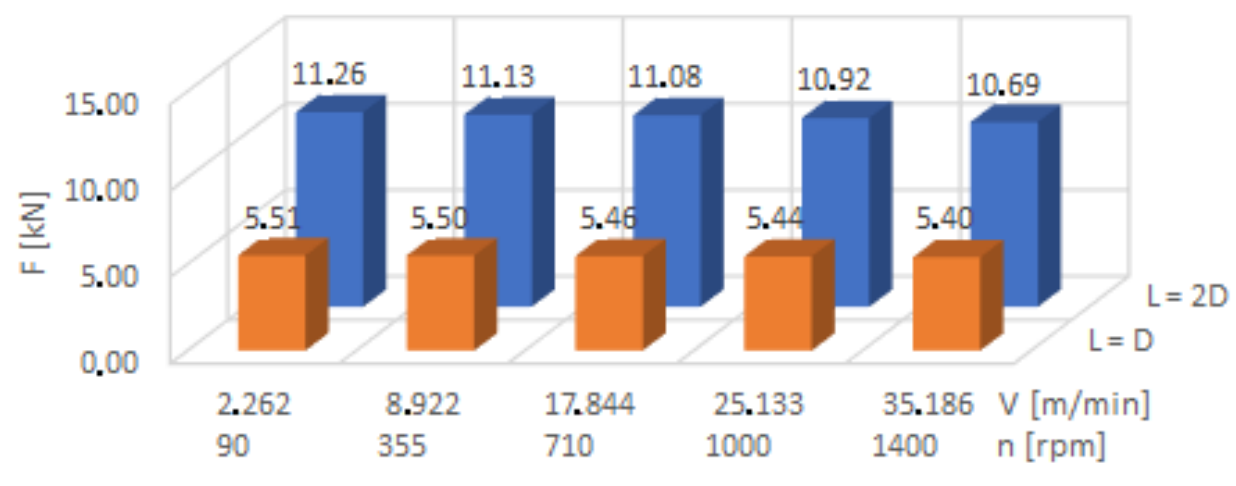

Figure 4.b. Comparation between the results of the experiments for $\mathrm{L}=2 \mathrm{D}, \mathrm{L}=\mathrm{D}$

In Figure 5 the graph one can see two maximum peaks. The first, higher, represents the force at which the threaded assembly the thread helix is destroyed by shearing. The second, smaller peak appears when, due to the movement of the screw rod, the sheared helix are blocked between the hole and the screw rod.

During the request experiments of the threaded assembly I observed:

When axially loading the thread manufactured in SikaBlock ${ }^{\circledR}$ M960 it has a different behavior from the behavior of the thread manufactured in metals or plastics (such as PEHD, PA, POM) where the helix of the inner thread is shear at the crest level of the external thread (Major Diameter). 


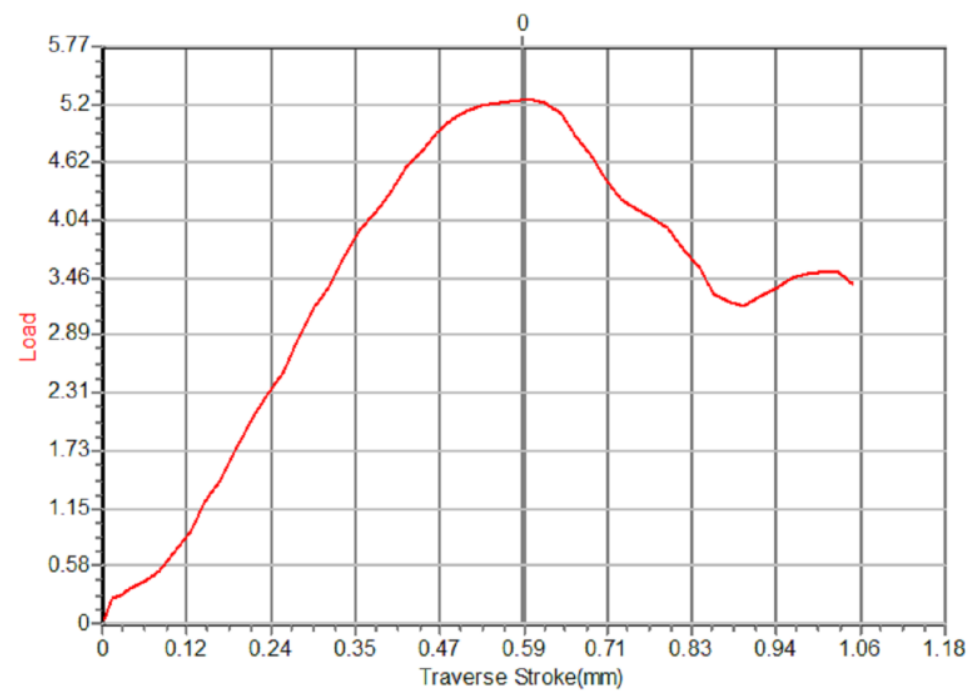

Figure 5. The load force variation for the threaded assembly

In the case of SikaBlock ${ }^{@}$ M960 besides the shear of the helix there is also a tearing of the material depending on the load scheme. In figure 5.a and 5.b present the test fixing mode in order to perform the tests.

Case 1, fig.6.a, the piece manufactured from SikaBlock ${ }^{@}$ M960, is the base structure, on which various parts are fixed. In this case, the phenomenon of tearing occurs besides shearing the helix.

Case 2, fig.6.b, the manufactured part, from SikaBlock ${ }^{\circledR}$ M960, is fixed to a resistance structure or is nut. In this case, the phenomenon of tearing does not appear, along the length of the thread. Only the shear of the helix appears.

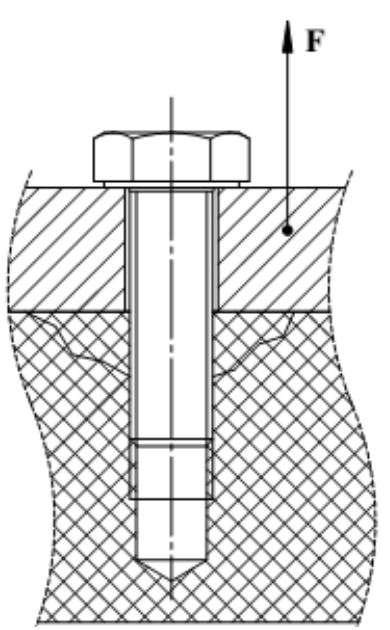

a.

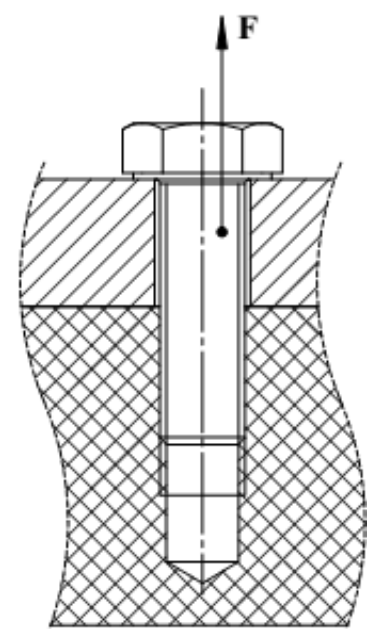

b.

Figure 6. Fixing mode to study the shearing and tearing of the thread helix

I repeated the experiment for the fixing variant 1, presented in fig. 6.a. The fastening method used allows the area near the screw to be uncoated and is shown in Figure 7.

In this case, the last helixes of the inner thread no longer shear, due to the load it appears the tearing of the material, having the shape of a cone trunks (figure 8). 
By measurement we determined the average of the dimensions of the tear cone trunks. The results of the measurements are presented in table 3 .

In table 4 present a comparison between the maximum load forces of thread according to the fixing mode.

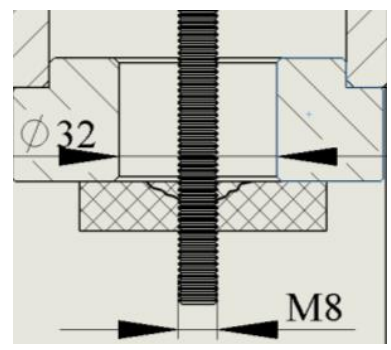

Figure 7. The fastening method to study the tearing of the thread helix.
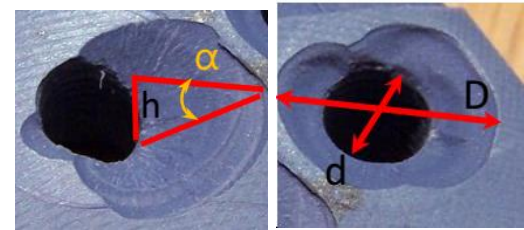

$\mathrm{L}=2 \mathrm{D}$

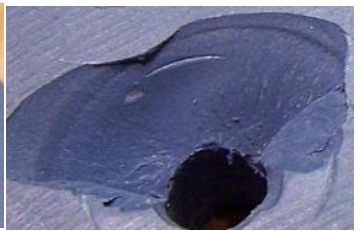

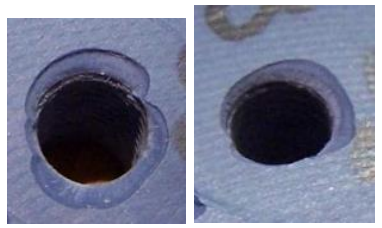

$\mathrm{L}=\mathrm{D}$

Figure 8. The tear cone trunks and his dimensions

Table 3. Dimensions of tear cone trunks.

\begin{tabular}{|c|c|c|c|c|}
\hline \multirow{2}{*}{} & \multicolumn{4}{|c|}{ Dimensions of cone trunks } \\
\cline { 2 - 4 } & $\begin{array}{c}\text { Major diameter } \\
\mathrm{D}[\mathrm{mm}]\end{array}$ & $\alpha\left[{ }^{\circ}{ }^{\prime} "\right]$ & $\begin{array}{c}\text { Height } \\
\mathrm{h}[\mathrm{mm}]\end{array}$ & $\begin{array}{c}\text { Minor diameter } \\
\mathrm{d}[\mathrm{mm}]\end{array}$ \\
\hline $\mathrm{L}=\mathrm{D}$ & 16.2 & $22^{\circ} 37^{\prime} 12^{\prime \prime}$ & 1.75 & $\begin{array}{c}7.8 \\
\text { (Obs. thread major diameter) }\end{array}$ \\
\hline $\mathrm{L}=2 \mathrm{D}$ & 31.8 & $22^{\circ} 34^{\prime} 10^{\prime \prime}$ & 5.5 & \\
\hline
\end{tabular}

Table 4. Maximum load forces according to the fixing mode.

\begin{tabular}{|c|c|c|c|c|c|}
\hline & \multirow{2}{*}{\multicolumn{2}{|c|}{$\frac{\mathrm{L}=2 \mathrm{D}(\mathrm{L}=16 \mathrm{~mm})}{\mathrm{F}[\mathrm{kN}]}$}} & & \multirow{5}{*}{$\begin{array}{l}2 \text { less than } \\
3 \text { with }\end{array}$} \\
\hline & & & & & \\
\hline & & \multirow{2}{*}{$\begin{array}{c}\text { Case 1, fig.5.a, } \\
\text { (tear + shear) }\end{array}$} & \multirow{2}{*}{$\begin{array}{c}\text { Case 2, fig.5.b, } \\
\text { (only shear) }\end{array}$} & & \\
\hline \multirow{3}{*}{$\begin{array}{c}\mathrm{n} \\
{\left[\mathrm{min}^{-1}\right]}\end{array}$} & \multirow{3}{*}{$\begin{array}{c}\mathrm{V} \\
{[\mathrm{m} / \mathrm{min}]}\end{array}$} & & & & \\
\hline & & 2 & 3 & $3-2$ & \\
\hline & & $\mathrm{kN}$ & $\mathrm{kN}$ & $\mathrm{kN}$ & $\%$ \\
\hline 710 & 17.844 & 7.60 & 11.082 & 3.48 & 31.42 \\
\hline 355 & 8.922 & 8.20 & 11.131 & 2.93 & 26.33 \\
\hline 90 & 2.262 & 8.33 & 11.256 & 2.93 & 26.00 \\
\hline
\end{tabular}

\section{Conclusions}

The cutting speed influences the thread resistance. As the cutting speed increases, the thread strength decreases. In the range of speeds $2.262-35.186 \mathrm{~m} / \mathrm{min}\left(90-1400 \mathrm{~min}^{-1}\right) \mathrm{I}$ find a decrease in force with: 
- $-5 \%$ in the case of the thread tested with the length $\mathrm{L}=2 \mathrm{D}$

$\circ-2 \%$ in the case of the thread tested with length $\mathrm{L}=\mathrm{D}$.

The helix of the inner thread, processed in SikaBlock, is shear at the level of thread major diameter, but a tear of material also appears, depending on the assembly requested mode.

The wall angle of the tear cone trunks stays the same, regardless the hole depth. Depending on the thread depth (number of turns), the length of the cone trunk and its major diameter grows.

Depending on the thread request mode, the resistance of the threaded assembly can decrease by $26-31.46 \%$.

Following the tests, I consider that it is necessary:

- To determine the size of the cone trunks for each type of SikaBlock material, establishing the minimum distance between two threaded holes.

- To study how the resistance of the thread are influenced by the tap chip evacuation directions [7]. The cutting force structure differs, it can influence the quality and resilience of the thread.

- To repeat the experiment using several sizes and thread types;

- To repeat the experiment using materials from the SikaBlock family with other mechanical qualities.

\section{References}

1. SikaBlock ${ }^{\circledR}$ M960 Product Data Sheet Version 02/2016

2. ISO 724:1993 ISO general-purpose metric screw threads — Basic dimensions

3. ISO 4017 Hexagon head screws - Product grades A and B

4. Manea Gh. Organe de masini. Editura Tehnica, Bucuresti, (1970).

5. Stranghöner N., Abraham C., Jungbluth D., RFCS-Project "SIROCO” (2018).

6. Fukuoka, T., CORONA Publishing Co. Ltd., (2015).

7. Walter AG, Threading with walter prototyp, Product handbook.. 